OPEN ACCESS

Edited by:

Ioan Opris,

University of Miami, United States

Reviewed by:

Giulia Corno,

Universitat de València, Spain

Lucia Valmaggia,

King's College London,

United Kingdom

France Hirot,

Fondation Santé des Etudiants de

France, France

${ }^{*}$ Correspondence:

Giuseppe Riva

giuseppe.riva@unicatt.it

Received: 29 November 2017 Accepted: 26 January 2018 Published: 12 February 2018

Citation:

Riva $G$ and Dakanalis A (2018) Altered Processing and Integration of Multisensory Bodily

Representations and Signals in Eating Disorders: A Possible Path

Toward the Understanding of Their Underlying Causes.

Front. Hum. Neurosci. 12:49. doi: 10.3389/fnhum.2018.00049

\section{Altered Processing and Integration of Multisensory Bodily Representations and Signals in Eating Disorders: A Possible Path Toward the Understanding of Their Underlying Causes}

\author{
Giuseppe Riva ${ }^{1,2 *}$ and Antonios Dakanalis ${ }^{3,4}$ \\ ${ }^{1}$ Centro Studi e Ricerche di Psicologia della Comunicazione, Università Cattolica del Sacro Cuore, Milan, Italy, ${ }^{2}$ Applied \\ Technology for Neuro-Psychology Laboratory, Istituto Auxologico Italiano (IRCCS), Milan, Italy, ${ }^{3}$ Department of Medicine and \\ Surgery, Università degli Studi di Milano Bicocca, Milan, Italy, ${ }^{4}$ Department of Brain and Behavioral Sciences, University of \\ Pavia, Pavia, Italy
}

According to the Diagnostic and Statistical Manual of Mental Disorders (DSM V) eating problems are the clinical core of eating disorders (EDs). However, the importance of shape and weight overvaluation symptoms in these disorders underlines the critical role of the experience of the body in the etiology of EDs. This article suggests that the transdiagnostic centrality of these symptoms in individuals with EDs may reflect a deficit in the processing and integration of multisensory bodily representations and signals. Multisensory body integration is a critical cognitive and perceptual process, allowing the individual to protect and extend her/his boundaries at both the homeostatic and psychological levels. To achieve this goal the brain integrates sensory data arriving from real-time multiple sensory modalities and internal bodily information with predictions made using the stored information about the body from conceptual, perceptual, and episodic memory. In this view the emotional, visual, tactile, proprioceptive and interoceptive deficits reported by many authors in individuals with EDs may reflect a broader impairment in multisensory body integration that affects the individual's abilities: (a) to identify the relevant interoceptive signals that predict potential pleasant (or aversive) consequences; and (b) to modify/correct the autobiographical allocentric (observer view) memories of body related events (self-objectified memories). Based on this view, the article also proposes a strategy, based on new technologies (i.e., virtual reality and brain/body stimulation), for using crossmodal associations to reactivate and correct the multisensory body integration processes.

\footnotetext{
Keywords: multisensory body integration, eating disorders, self-objectification, interoception, body dissatisfaction, virtual reality, body memory, body representations
}

\section{INTRODUCTION}

The American Psychiatric Association's (APA) Diagnostic and Statistical Manual of Mental Disorders (DSM V) identifies eating problems as the clinical core of eating disorders (EDs). However, the importance of shape and weight overvaluation symptoms in these disorders underlines the critical role of the experience of the body in their etiology. This vision is strengthened 
by the results of two 4-year longitudinal studies-the first involving 2713 female college students (Dakanalis et al., 2017a), and the second including 2507 male college students (Dakanalis et al., 2016c) - recently completed by our team. Both studies explored the role played by theoretically relevant factors in predicting the onset and maintenance of EDs. In both samples self-objectification, body dissatisfaction, appearanceideal internalization, dieting and negative affectivity at baseline, as well as changes in these factors, predicted onset and maintenance of DSM-5 EDs at 4-year follow-up. Even if all these vulnerability factors are traditionally accepted as having a critical role in the emergence and maintenance of EDs (Calogero et al., 2010; Culbert et al., 2015) the newness of the two studies is the different predictive value of the assessed factors. First, the relative variance explained by body dissatisfaction and appearance-ideal internalization (the extent to which one sets culturally defined appearance ideals as his/her own personal standard of attractiveness) is almost two times the variance explained by dieting and by negative affectivity. Furthermore, the relative variance explained by self-objectification (the tendency to experience one's body from an external observer's perspective) is almost four times the variance explained by dieting, and more than four time the variance explained by negative affectivity, at least for females.

Apparently, these and other results (Dakanalis et al., 2014, 2015a,c, 2016a,d; Kearney-Cooke and Tieger, 2015) suggests an important role of the experience of the body in the emergence and maintenance of EDs (Dakanalis et al., 2016b), even if the causal path has not been fully elucidated, in particular for bingeeating subjects (Grilo et al., 2005; Herbozo et al., 2015).

More, these results are in line with the tenets of the Objectification Theory (Fredrickson and Roberts, 1997). This theory suggests that the pressure to constantly monitor and scrutinize our body from outside, to ensure its conformity with cultural standards (Calogero et al., 2017), encourages specific cognitions and behaviors that leads to increased body shame and subsequent EDs (Fitzsimmons-Craft et al., 2011; Kroon Van Diest and Perez, 2013; Dakanalis et al., 2017c). However, the situation is more complex than it might seem to be at first sight (Dakanalis et al., 2015b). As recently reported by Holland et al. (2017), objectifying events are frequently experienced by young women: the authors reported that women experienced objectifying events approximately once every 2 days and witnessed them more than once per day. The pervasivity of this experience is also reflected by the level of dissatisfaction: two online cross-sectional studies (Runfola et al., 2013), the UNC-SELF study and the Gender and Body Image Study (GABI), involving more than 5868 women residing in the United States, found that $90.0 \%$ of the women in the $25-34$ age bracket and 93.2\% in the 35-44 age bracket experienced body dissatisfaction. Nevertheless, the percentage of female individuals who met DSM-5 criteria for an ED diagnosis is much lower: in our samples $13.1 \%$ of college women at baseline and $7.6 \%$ at 4 -year follow-up.

Even if self-objectification is a critical risk factor for the development of EDs, the Objectification Theory is still not able to answer two critical questions: Why do not all the individuals experiencing self-objectification develop EDs? What is the role of the body experience in the etiology of these disorders?

Here we will embrace an emerging field of neuroscience-the multisensory integration of bodily representations and signals-to answer the above questions. Specifically, the first goal of this manuscript is to describe a plausible, testable and transdiagnostic model of EDs centered on multisensory body integration deficits. Secondly, we also suggest possible techniques based on the presented model to correct these deficits.

\section{MULTISENSORY BODY INTEGRATION IN BRIEF}

The feeling of being a "real me" that emerges from one's body- "bodily self-consciousness"-is one of the most complex experiences produced by the human mind (Moseley et al., 2012). In fact, it is the result of the multisensory integration (Figure 1) of many different sources of information (Riva, 2017b). The final outcome of this process, resulting from the connections between the posterior parietal cortex and the insular cortex, is a coarse supramodal multi-sensory representation of the body and the space around it, the "body matrix" (Moseley et al., 2012).

As recently noted by Barrett (2017): "For a brain to effectively regulate its body in the world, it runs an internal model of that body in the world" (p. 5). And this is the main goal of the body matrix: to predict (i) upcoming sensory events both inside and outside the body; (ii) how to use the body for dealing with them (Barrett, 2017). Specifically, its evolutive goal is to ensure resources to promote survival and reproduction (allostasis) by protecting and extending its boundaries at both the homeostatic and psychological level (Sterling, 2012; Barrett et al., 2016).

To produce the body matrix, data arriving from real-time multiple sensory modalities (exteroception; i.e., touch and vision) are first integrated with internal information (i.e., interoception and proprioception). The outcome of this process is then recalibrated according to predictions made using the stored information about the body from conceptual (i.e., the meaning attributed to the body), perceptual (i.e., the size and the shape of the body), and episodic (i.e., the key autobiographical events related to the experience of the body) memory.

The process of multisensory integration also imposes coherence on divergent bodily information by minimizing the amount of prediction errors (or "surprise") about the expected sensory input (Hohwy, 2013). Specifically, the contents of the body matrix are adjusted evaluating the (dis)agreement (Talsma, 2015) between the perceived sensory activity, and the activity predicted through the integration of contents from different bodily and cognitive representations.

Once these errors are minimized, the body matrix provides predictions about the causes of sensory events and plans for coping with them both internally (i.e., producing a change in 


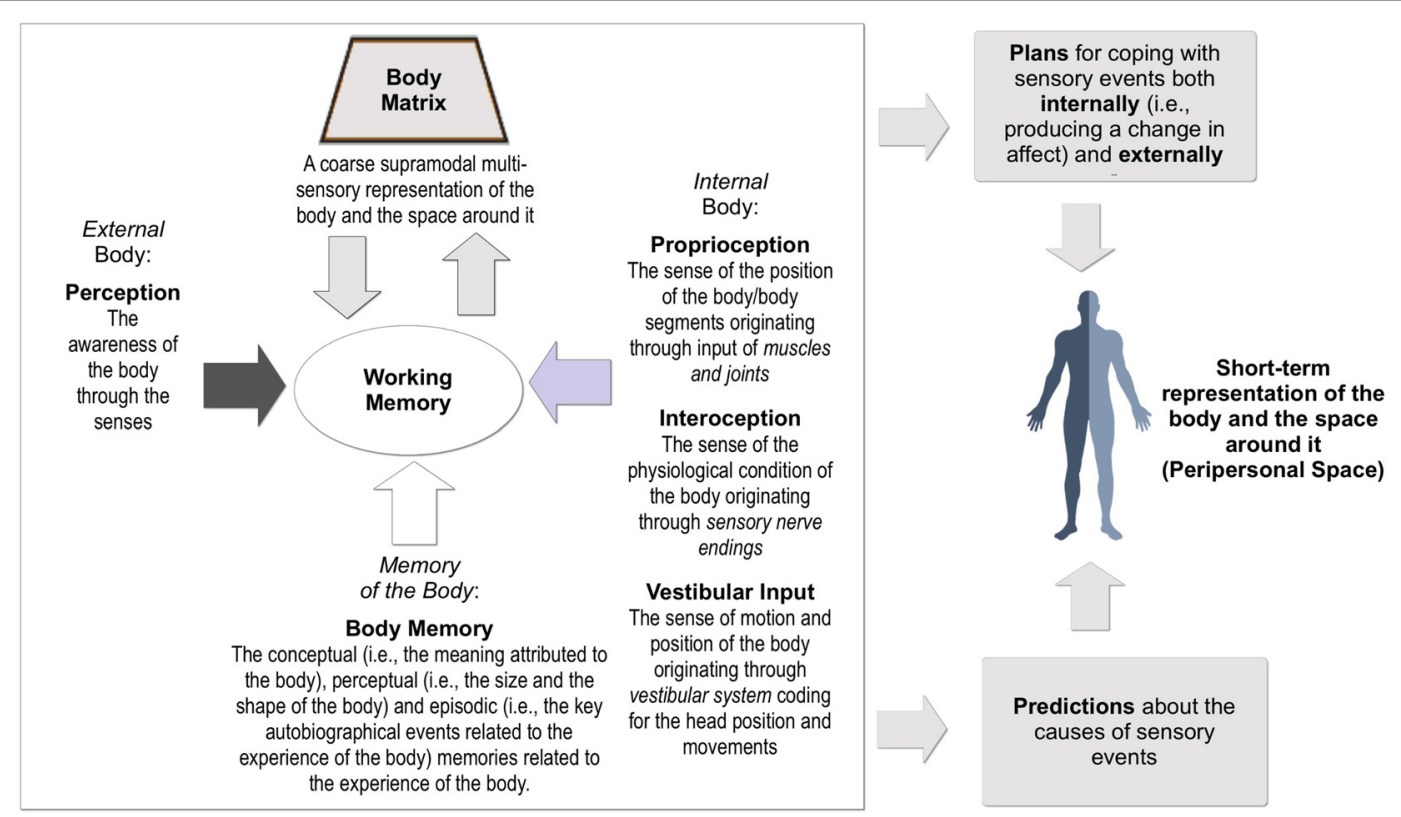

FIGURE 1 | Multisensory integration of bodily signals.

affect; Seth et al., 2012) and externally (i.e., by defining an action plan; Wang et al., 2014).

Every bodily sensation can have many different causes and effects. To recognize and cope with them in advance, our brain uses a complex process of predictive multisensory integration (Riva, 2017b).

In this view, the experience of the body is the result of a probabilistic process and, as such, may not reflect the characteristics of the physical body (Badoud and Tsakiris, 2017; Ferri et al., 2017). More, this vision suggests that the above multisensory processes do not influence the experience of the body only, but can also affect emotion regulation (Riva, 2017b; Tseng et al., 2015).

Specifically, emotions are not seen any more as iterative stimulus-response sequences, but as bodily simulations that, according to the individual's previous experience, are labeled as emotions. As clarified by Barrett (2017): "That is, the brain constructs meaning by correctly anticipating (predicting and adjusting to) incoming sensations. Sensations are categorized so that they are: (i) actionable in a situated way; and therefore (ii) meaningful, based on past experience. When past experiences of emotion (e.g., happiness) are used to categorize the predicted sensory array and guide action, then one experiences or perceives that emotion (happiness)." (p. 9).

Finally, if both emotions and the experience of the body are the outcome of a complex process of predictive multisensory integration, their content will be impaired by a deficit in the process. In this view, damage, malfunctioning, or altered feedback from and toward the body matrix might be involved in the etiology of EDs. In the next pages we will try to deepen this point.

\section{MULTISENSORY IMPAIRMENTS IN EATING DISORDERS}

As reported by various authors, individuals with EDs have emotional (Bydlowski et al., 2005; Lavender et al., 2015), visual (Engel and Keizer, 2017; Feusner et al., 2017), tactile (Keizer et al., 2011; Gaudio et al., 2014), proprioceptive (Case et al., 2012; Guardia et al., 2012) and interoceptive deficits (Badoud and Tsakiris, 2017; Klabunde et al., 2017).

Typically, these deficits have been assessed and examined specifically. However, as we have just seen, these different sources are all shaped by the process of predictive multisensory integration. More, we know that different processes (i.e., working memory), neurotransmitters (i.e., serotonin) and brain areas related to multisensory integration (i.e., frontal and parietal lobes) are impaired in individuals with EDs (Gaudio et al., 2016; Riva, 2016; Brooks et al., 2017).

This led us to hypothesize that these deficits may reflect a broader impairment in multisensory body integration (Zopf et al., 2016; Riva, 2017b; Riva and Gaudio, 2017). Specifically, following the emerging literature on this topic, it is possible to identify at least two different multisensory deficits (Riva, 2017b):

1. An impairment in the ability to correctly link internal (interoceptive) bodily signals to their potential pleasant (or aversive) consequences. According to Paulus and Stein (2010), a brain circuit that involves the medial prefrontal cortex, the dorsolateral prefrontal cortex and the anterior cingulate, evaluates anticipatory interoceptive signals using self-relevant and belief-based processes to identify those that are relevant. If this process is impaired, the individual can no longer correctly identify the relevant 
interoceptive signals that predict potential pleasant (or aversive) consequences. This situation produces significant impairments that affect the emotional abilities of the individual. First, it causes deficits in emotional clarity (i.e., recognizing and distinguishing between emotional signals) and emotional awareness (i.e., attention to emotions). Second, it impairs emotion regulation. Indeed, on one side, the individuals are not able to identify and use appropriate strategies to modulate the duration and/or intensity of emotional responses. On the other side, they experience greater difficulties in behavioral control when distressed and may decide to avoid emotion eliciting situations (Caslini et al., 2016). As noted by a recent review by Lavender et al. (2015), all these dimensions of emotion dysregulation can be found in both anorexia and bulimia nervosa.

2. An impairment in the ability to update body memory (allocentric, offline) with new content from real-time perception-driven inputs (egocentric, online). As we have just seen, self-objectification is a critical risk factor for the development of EDs. But what is self-objectification from a neuropsychological view point? As we suggested previously (Riva et al., 2015) individuals objectify themselves when they use an allocentric frame of reference (i.e., using an observer's viewpoint) to remember events in which they evaluate themselves based upon bodily appearance (i.e., my boyfriend telling me "You are fat. Your belly is so big"). To be included in the body matrix, these higher level long-term allocentric bodily memories have to be integrated with lower level real-time egocentric (i.e., first-person viewpoint) sensory signals (Mou et al., 2004). According to a prominent neural model of spatial memory and imagery (Byrne et al., 2007; Byrne and Becker, 2008), the translation between these representations involves the retrosplenial cortex, with the support of place and grid cells. In their own words: "Both encoding and retrieval/imagery require translation between egocentric and allocentric representations, which are mediated by posterior parietal and retrosplenial areas and the use of head direction representations in Papez's circuit" (p. 340). If this process is impaired, the individual is not able to update the stored representation of the body with new real-time sensory data (Allocentric Lock). This situation produces significant impairments that affect the body experience of the individual (Serino et al., 2015). The first and most important is that the individual is no more able to modify/correct the autobiographical allocentric (observer view) memories of body related events (self-objectified memories) even if the body has changed (i.e., the memory of a fat belly, even if the belly is no more fat). This situation locks the individual to a permanent body shame that cannot be countered, pushing her/him towards EDs (Riva, 2012, 2014; Riva and Gaudio, 2012). More, these memories, through the predictive coding, structure the interpretation and acquisition of new ones (Riva et al., 2015). In simpler words, they generate a priming effect on any body related experience filtering from new experiences only the contents relevant to its meaning (i.e., the girl looking at my belly is smiling because it is fat).

\section{RESTORING THE NORMAL FUNCTIONING OF MULTISENSORY BODY INTEGRATION}

As we have seen before, the body matrix uses predictive coding and crossmodal processing, (i.e., the integration in a single representation of distinct inputs from sensorial modalities) to obtain coherence from discordant sensory information. This process suggests the possibility of updating the contents of the body matrix through the generation of new crossmodal associations between bodily stimuli that have not been previously experienced as systematically related. Specifically, crossmodal associations can produce crossmodal illusions (Bolognini et al., 2015): the contents of one sensory modality affect what we experience in another modality. In this context, crossmodal illusions may have two different roles. On one side, they can be used as assessment tools to verify an abnormal multisensory body integration. On the other side, they can reactivate and correct the contents of the body matrix. In fact, if the new crossmodal association is able to produce a significant prediction error (high surprise), it should be able to update the predictive internal models of the body matrix (Riva et al., 2017a).

It is interesting to note that "The body project", the most effective and validated prevention program for EDs (Stice et al., 2011; Stice, 2016; Becker and Stice, 2017) developed by Eric Stice and his team, does not focus on eating or nutrition. Instead it uses a new affective/cognitive crossmodal association (negative emotions and the thin-ideal body standard to reduce thin-ideal internalization and appearance-related social comparison tendencies. Specifically in the program individuals voluntarily critique the thin-ideal standard of female beauty via verbal, written and behavioral exercises.

The appearance of new technologies and in particular the broader availability of virtual reality - a technology that has been already used successfully both to study body schema representations and distortions in normal and clinical population (Riva, 1998; Ferrer-García and Gutiérrez-Maldonado, 2010; Preston and Ehrsson, 2014, 2016; Mölbert et al., 2017), and in the treatment of EDs (Gutiérrez-Maldonado et al., 2016, 2017; Riva, 2017a)-offers new ways to provide crossmodal associations (Riva et al., 2017b; Tajadura-Jiménez et al., 2017; Weser et al., 2017) that can be used in clinical practice (Dakanalis et al., 2017b; Serino and Dakanalis, 2017). For example, different recent studies using virtual reality (VR)-based body swapping-a novel technology-based crossmodal association between vision (a new virtual reality [VR] body) and touch (the real body)-provided preliminary support to this approach, allowing a significant improvement in the ability to correctly estimate body size in both nonclinical (Preston and Ehrsson, 2014; Ferrer-Garcia et al., 2017) and clinical samples (Keizer et al., 2016; Serino et al., 2016a,b).

At the moment these bodily illusions provide a short-term effect only (Keizer et al., 2016). However, this result may be improved by using more advanced crossmodal associations that also target inner body signals (i.e., interoceptive, proprioceptive and vestibular signals). To reach this goal, VR has to be integrated with bio/neuro-feedback and/or brain/body stimulation technologies able to measure and modulate the 
internal body experience (Riva et al., 2017a). For example, the use of heart rate variability and respiratory sinus arrhythmia biofeedback can be used to enhance interoceptive sensitivity and the appraisal of interoceptive bodily signals (Herbert et al., 2013; Tajadura-Jiménez and Tsakiris, 2014).

\section{DISCUSSION}

Shape and weight overvaluation are considered core symptoms of EDs. In this article, we suggested that the transdiagnostic centrality of shape and weight overvaluation in individuals with EDs may reflect a broader impairment in multisensory body integration. Multisensory body integration is a critical cognitive and perceptual process, allowing the individual to protect and extend her/his boundaries at both the homeostatic and psychological levels (Riva, 2017b). More, it is not an innate ability but the result of a long developmental process, reaching maturity only at the age of $10-11$, through which the individual is able to define and compare her/his own body in relation to an ideal cultural body defined by institutional norms and values (Riva, 2017b). As discussed before, this process integrates sensory data arriving from real-time multiple sensory modalities and internal information with predictions made using the stored information about the body from conceptual, perceptual and episodic memory.

In this vision, multisensory integration deficits represent a failure in this functional adaptation process, which may impair the emotional and bodily experience of the individual.

Starting from the above premises, in this article we provided a plausible and testable theory of the etiology of EDs based on impairments in:

1. The ability to link internal (interoceptive) bodily signals to their potential pleasant (or aversive) consequences, and

2. The ability to update body memory (allocentric, offline) with new content from real-time perception-driven inputs (egocentric, online).

This theory has three strengths. First, it offers a plausible and testable model able to explain the etiology of these disorders. Specifically, to test it we need to assess multisensory integration deficits in EDs and use a longitudinal study to examine the influence of this vulnerability factor in predicting both the onset and maintenance of (DSM-5) EDs in the long term.

Second, it provides the rationale for a novel multisensory technology aiming at restoring the normal functioning of these

\section{REFERENCES}

Badoud, D., and Tsakiris, M. (2017). From the body's viscera to the body's image: is there a link between interoception and body image concerns? Neurosci. Biobehav. Rev. 77, 237-246. doi: 10.1016/j.neubiorev.2017. 03.017

Barrett, L. F. (2017). The theory of constructed emotion: an active inference account of interoception and categorization. Soc. Cogn. Affect. Neurosci. 12, 1-23. doi: 10.1093/scan/nsw154

Barrett, L. F., Quigley, K. S., and Hamilton, P. (2016). An active inference theory of allostasis and interoception in depression. Philos. Trans. R. Soc. Lond. B Biol. Sci. 371:20160011. doi: 10.1098/rstb.2016.0011 processes. Specifically, it provides a rationale for using new technologies (i.e., virtual reality and brain/body stimulation) to target crossmodal associations to reactivate and correct multisensory body integration processes.

A final key strength of this vision is that it proposes a translational neuroscience perspective, effectively integrating some of the existing prominent etiological models of EDs. On one side, multisensory deficits produce a dysfunctional system for evaluating self-worth in line with the assumptions of the transdiagnostic cognitive behavioral theory (Fairburn, 2008; Cooper and Fairburn, 2011) models. Moreover, the critical role of stress and anxiety related issues in producing multisensory body integration deficits is in agreement with the revised cognitive-interpersonal maintenance model and the theory of emotional eating (Schmidt and Treasure, 2006; Treasure and Schmidt, 2013). Finally, it allows us to better explain the role of self-objectification in EDs: the onset and maintenance of EDs is not related to the experience of self-objectification in itself but to the impossibility of countering the body shame produced by it, even when the real body of the subject is in line with the thin-ideal standard of beauty.

In conclusion, although various studies support a possible role of multisensory body integration deficits in the etiology of EDs and link them to body and emotional problems in individuals with EDs there are still numerous open questions: What are their causes? Are they different for the individual EDs? Are there ways to protect against them? Are there gender differences? How can we modify them? Extensive new interdisciplinary research is required to confirm this hypothesis and to provide meaningful answers to all these questions.

\section{AUTHOR CONTRIBUTIONS}

GR conceived and developed the initial draft, contributed to the enhancement of the original draft, and participated in developing the final draft; $\mathrm{AD}$ worked with GR to enhance the original draft and develop it into the final draft; both authors have reviewed and approved the final manuscript as submitted.

\section{FUNDING}

This article was supported by the Italian Ministero dell'Istruzione, dell'Università e della Ricerca (MIUR) research project "Unlocking the memory of the body: Virtual Reality in Anorexia Nervosa" (201597WTTM).

Becker, C. B., and Stice, E. (2017). From efficacy to effectiveness to broad implementation: evolution of the Body Project. J. Consult. Clin. Psychol. 85, 767-782. doi: 10.1037/ccp0000204

Bolognini, N., Russo, C., and Vallar, G. (2015). Crossmodal illusions in neurorehabilitation. Front. Behav. Neurosci. 9:212. doi: 10.3389/fnbeh.2015. 00212

Brooks, S. J., Funk, S. G., Young, S. Y., and Schiöth, H. B. (2017). The role of working memory for cognitive control in anorexia nervosa versus substance use disorder. Front. Psychol. 8:1651. doi: 10.3389/fpsyg.2017.01651

Bydlowski, S., Corcos, M., Jeammet, P., Paterniti, S., Berthoz, S., Laurier, C., et al. (2005). Emotion-processing deficits in eating disorders. Int. J. Eat. Disord. 37, 321-329. doi: 10.1002/eat.20132 
Byrne, P., and Becker, S. (2008). A principle for learning egocentric-allocentric transformation. Neural Comput. 20, 709-737. doi: 10.1162/neco.2007.1006-361

Byrne, P., Becker, S., and Burgess, N. (2007). Remembering the past and imagining the future: a neural model of spatial memory and imagery. Psychol. Rev. 114, 340-375. doi: 10.1037/0033-295x.114.2.340

Calogero, R. M., Tantleff-Dunn, S., and Thompson, J. K. (2010). Self-Objectification in Women: Causes, Consequences, and Counteractions. Washington, DC: American Psychological Association.

Calogero, R. M., Tylka, T. L., Donnelly, L. C., McGetrick, A., and Leger, A. M. (2017). Trappings of femininity: a test of the "beauty as currency" hypothesis in shaping college women's gender activism. Body Image 21, 66-70. doi: 10.1016/j. bodyim.2017.02.008

Case, L. K., Wilson, R. C., and Ramachandran, V. S. (2012). Diminished size-weight illusion in anorexia nervosa: evidence for visuo-proprioceptive integration deficit. Exp. Brain Res. 217, 79-87. doi: 10.1007/s00221-011-2974-7

Caslini, M., Bartoli, F., Crocamo, C., Dakanalis, A., Clerici, M., and Carrà, G. (2016). Disentangling the association between child abuse and eating disorders: a systematic review and meta-analysis. Psychosom. Med. 78, 79-90. doi: 10.1097/PSY.0000000000000233

Cooper, Z., and Fairburn, C. G. (2011). The evolution of "enhanced" cognitive behavior therapy for eating disorders: learning from treatment nonresponse. Cogn. Behav. Pract. 18, 394-402. doi: 10.1016/j.cbpra.2010.07.007

Culbert, K. M., Racine, S. E., and Klump, K. L. (2015). Research review: what we have learned about the causes of eating disorders-a synthesis of sociocultural, psychological, and biological research. J. Child Psychol. Psychiatry 56, 1141-1164. doi: 10.1111/jcpp.12441

Dakanalis, A., Carrà, G., Calogero, R., Fida, R., Clerici, M., Zanetti, M. A., et al. (2015a). The developmental effects of media-ideal internalization and self-objectification processes on adolescents' negative body-feelings, dietary restraint and binge eating. Eur. Child Adolesc. Psychiatry 28, 997-1010. doi: 10.1007/s00787-014-0649-1

Dakanalis, A., Carrà, G., Clerici, M., and Riva, G. (2015b). Efforts to make clearer the relationship between body dissatisfaction and binge eating. Eat. Weight Disord. 20, 145-146. doi: 10.1007/s40519-014-0152-1

Dakanalis, A., Favagrossa, L., Clerici, M., Prunas, A., Colmegna, F., Zanetti, M. A., et al. (2015c). Body dissatisfaction and eating disorder symptomatology: a latent structural equation modeling analysis of moderating variables in 18-to-28-yearold males. J. Psychol. 149, 85-112. doi: 10.1080/00223980.2013.842141

Dakanalis, A., Clerici, M., Caslini, M., Gaudio, S., Serino, S., Riva, G., et al. (2016a). Predictors of initiation and persistence of recurrent binge eating and inappropriate weight compensatory behaviors in college men. Int. J. Eat. Disord. 49, 581-590. doi: 10.1002/eat.22535

Dakanalis, A., Gaudio, S., Serino, S., Clerici, M., Carrà, G., and Riva, G. (2016b). Body-image distortion in anorexia nervosa. Nat. Rev. Dis. Primers 2:16026. doi: $10.1038 /$ nrdp. 2016.26

Dakanalis, A., Pla-Sanjuanelo, J., Caslini, M., Volpato, C., Riva, G., Clerici, M., et al. (2016c). Predicting onset and maintenance of men's eating disorders. Int. J. Clin. Health Psychol. 16, 247-255. doi: 10.1016/j.ijchp.2016.05.002

Dakanalis, A., Timko, A., Serino, S., Riva, G., Clerici, M., and Carrà, G. (2016d). Prospective psychosocial predictors of onset and cessation of eating pathology amongst college women. Eur. Eat. Disord. Rev. 24, 251-256. doi: 10.1002/ erv. 2433

Dakanalis, A., Clerici, M., Bartoli, F., Caslini, M., Crocamo, C., Riva, G., et al. (2017a). Risk and maintenance factors for young women's DSM-5 eating disorders. Arch. Womens Ment. Health 11, 721-731. doi: 10.1007/s00737-0170761-6

Dakanalis, A., Manzoni, G. M., Castelnuovo, G., Riva, G., and Clerici, M. (2017b). Towards novel paradigms for treating dysfunctional bodily experience in eating disorders. Eat. Weight Disord. 22, 373-375. doi: 10.1007/s40519-0170361-5

Dakanalis, A., Timko, A. C., Clerici, M., Riva, G., and Carrà, G. (2017c). Objectified body consciousness (OBC) in eating psychopathology. Assessment 24, 252-274. doi: $10.1177 / 1073191115602553$

Dakanalis, A., Timko, C. A., Carrà, G., Clerici, M., Zanetti, M. A., Riva, G., et al. (2014). Testing the original and the extended dual-pathway model of lack of control over eating in adolescent girls. A two-year longitudinal study. Appetite 82, 180-193. doi: 10.1016/j.appet.2014.07.022
Engel, M. M., and Keizer, A. (2017). Body representation disturbances in visual perception and affordance perception persist in eating disorder patients after completing treatment. Sci. Rep. 7:16184. doi: 10.1038/s41598-017-16362-w

Fairburn, C. G. (2008). Cognitive Behavior Therapy and Eating Disorders. New York, NY: Guilford Press.

Ferrer-García, M., and Gutiérrez-Maldonado, J. (2010). Effect of the mood produced by virtual reality exposure on body image disturbances. Stud. Health Technol. Inform. 154, 44-49. doi: 10.3233/978-1-60750-561-7-44

Ferrer-Garcia, M., Porras-Garcia, B., González-Ibañez, C., Gracia-Blanes, M., Vilalta-Abella, F., Pla-Sanjuanelo, J., et al. (2017). "Does owning a "fatter" virtual body increase body anxiety in college students?" in Proceedings of the 2nd Annual CyberPsychology, CyberTherapy \& Social Networking Conference, (England: University of Wolverhampton), 147-151. Available online at: http://www.arctt.info/volume-15-summer-2017

Ferri, F., Ambrosini, E., Pinti, P., Merla, A., and Costantini, M. (2017). The role of expectation in multisensory body representation-neural evidence. Eur. J. Neurosci. 46, 1897-1905. doi: 10.1111/ejn.13629

Feusner, J., Deshpande, R., and Strober, M. (2017). A translational neuroscience approach to body image disturbance and its remediation in anorexia nervosa. Int. J. Eat. Disord. 50, 1014-1017. doi: 10.1002/eat.22742

Fitzsimmons-Craft, E. E., Bardone-Cone, A. M., and Kelly, K. A. (2011). Objectified body consciousness in relation to recovery from an eating disorder. Eat. Behav. 12, 302-308. doi: 10.1016/j.eatbeh.2011.09.001

Fredrickson, B. L., and Roberts, T. (1997). Objectification theory: toward understanding women's lived experiences and mental health risks. Psychol. Women Q. 21, 173-206. doi: 10.1111/j.1471-6402.1997.tb00108.x

Gaudio, S., Brooks, S. J., and Riva, G. (2014). Nonvisual multisensory impairment of body perception in anorexia nervosa: a systematic review of neuropsychological studies. PLoS One 9:e110087. doi: 10.1371/journal.pone. 0110087

Gaudio, S., Wiemerslage, L., Brooks, S. J., and Schioth, H. B. (2016). A systematic review of resting-state functional-MRI studies in anorexia nervosa: evidence for functional connectivity impairment in cognitive control and visuospatial and body-signal integration. Neurosci. Biobehav. Rev. 71, 578-589. doi: 10.1016/j. neubiorev.2016.09.032

Grilo, C. M., Masheb, R. M., Brody, M., Burke-Martindale, C. H., and Rothschild, B. S. (2005). Binge eating and self-esteem predict body image dissatisfaction among obese men and women seeking bariatric surgery. Int. J. Eat. Disord. 37, 347-351. doi: 10.1002/eat.20130

Guardia, D., Cottencin, O., Thomas, P., Dodin, V., and Luyat, M. (2012). Spatial orientation constancy is impaired in anorexia nervosa. Psychiatry Res. 195, 56-59. doi: 10.1016/j.psychres.2011.08.003

Gutiérrez-Maldonado, J., Ferrer-Garcia, M., Dakanalis, A., and Riva, G. (2017). "Virtual reality: applications to eating disorders," in The Oxford Handbook of Eating Disorders, Second Edition, eds S. W. Agras and A. Robinson (Oxford: Oxford University Press), 146-161.

Gutiérrez-Maldonado, J., Wiederhold, B. K., and Riva, G. (2016). Future directions: how virtual reality can further improve the assessment and treatment of eating disorders and obesity. Cyberpsychol. Behav. Soc. Netw. 19, 148-153. doi: 10.1089/cyber.2015.0412

Herbert, B. M., Blechert, J., Hautzinger, M., Matthias, E., and Herbert, C. (2013). Intuitive eating is associated with interoceptive sensitivity. Effects on body mass index. Appetite 70, 22-30. doi: 10.1016/j.appet.2013.06.082

Herbozo, S., Schaefer, L. M., and Thompson, J. K. (2015). A comparison of eating disorder psychopathology, appearance satisfaction and self-esteem in overweight and obese women with and without binge eating. Eat. Behav. 17, 86-89. doi: 10.1016/j.eatbeh.2015.01.007

Hohwy, J. (2013). The Predictive Mind. Oxford: Oxford University Press.

Holland, E., Koval, P., Stratemeyer, M., Thomson, F., and Haslam, N. (2017). Sexual objectification in women's daily lives: a smartphone ecological momentary assessment study. Br. J. Soc. Psychol. 56, 314-333. doi: 10.1111/bjso. 12152

Kearney-Cooke, A., and Tieger, D. (2015). "Body image disturbance and the development of eating disorders," in The Wiley Handbook of Eating Disorders, eds L. Smolak and M. P. Levine (West Sussex: Wiley), 283-296.

Keizer, A., Smeets, M. A., Dijkerman, H. C., van den Hout, M., Klugkist, I., van Elburg, A., et al. (2011). Tactile body image disturbance in anorexia nervosa. Psychiatry Res. 190, 115-120. doi: 10.1016/j.psychres.2011.04.031 
Keizer, A., van Elburg, A., Helms, R., and Dijkerman, H. C. (2016). A virtual reality full body illusion improves body image disturbance in anorexia nervosa. PLoS One 11:e0163921. doi: 10.1371/journal.pone.0163921

Klabunde, M., Collado, D., and Bohon, C. (2017). An interoceptive model of bulimia nervosa: a neurobiological systematic review. J. Psychiatr. Res. 94, 36-46. doi: 10.1016/j.jpsychires.2017.06.009

Kroon Van Diest, A. M., and Perez, M. (2013). Exploring the integration of thin-ideal internalization and self-objectification in the prevention of eating disorders. Body Image 10, 16-25. doi: 10.1016/j.bodyim.2012.10.004

Lavender, J. M., Wonderlich, S. A., Engel, S. G., Gordon, K. H., Kaye, W. H., and Mitchell, J. E. (2015). Dimensions of emotion dysregulation in anorexia nervosa and bulimia nervosa: a conceptual review of the empirical literature. Clin. Psychol. Rev. 40, 111-122. doi: 10.1016/j.cpr.2015.05.010

Mölbert, S. C., Klein, L., Thaler, A., Mohler, B. J., Brozzo, C., Martus, P., et al. (2017). Depictive and metric body size estimation in anorexia nervosa and bulimia nervosa: a systematic review and meta-analysis. Clin. Psychol. Rev. 57, 21-31. doi: 10.1016/j.cpr.2017.08.005

Moseley, G. L., Gallace, A., and Spence, C. (2012). Bodily illusions in health and disease: physiological and clinical perspectives and the concept of a cortical 'body matrix'. Neurosci. Biobehav. Rev. 36, 34-46. doi: 10.1016/j.neubiorev. 2011.03.013

Mou, W., McNamara, T. P., Valiquette, C. M., and Rump, B. (2004). Allocentric and egocentric updating of spatial memories. J. Exp. Psychol. Learn. Mem. Cogn. 30, 142-157. doi: 10.1037/0278-7393.30.1.142

Paulus, M. P., and Stein, M. B. (2010). Interoception in anxiety and depression. Brain Struct. Funct. 214, 451-463. doi: 10.1007/s00429-010-0258-9

Preston, C., and Ehrsson, H. H. (2014). Illusory changes in body size modulate body satisfaction in a way that is related to non-clinical eating disorder psychopathology. PLoS One 9:e85773. doi: 10.1371/journal.pone.0085773

Preston, C., and Ehrsson, H. H. (2016). Illusory obesity triggers body dissatisfaction responses in the insula and anterior cingulate cortex. Cereb. Cortex 26, 4450-4460. doi: 10.1093/cercor/bhw313

Riva, G. (1998). Virtual Reality vs. Virtual Body: the use of virtual environments in the treatment of body experience disturbances. Cyberpsychol. Behav. 1, 129-137. doi: $10.1089 / \mathrm{cpb} .1998 .1 .129$

Riva, G. (2012). Neuroscience and eating disorders: the allocentric lock hypothesis. Med. Hypotheses 78, 254-257. doi: 10.1016/j.mehy.2011.10.039

Riva, G. (2014). Out of my real body: cognitive neuroscience meets eating disorders. Front. Hum. Neurosci. 8:236. doi: 10.3389/fnhum.2014.00236

Riva, G. (2016). Neurobiology of anorexia nervosa: serotonin dysfunctions link self-starvation with body image disturbances through an impaired body memory. Front. Hum. Neurosci. 10:600. doi: 10.3389/fnhum.2016.00600

Riva, G. (2017a). Letter to the Editor: virtual reality in the treatment of eating and weight disorders. Psychol. Med. 47, 2567-2568. doi: 10.1017/ s0033291717001441

Riva, G. (2017b). The neuroscience of body memory: from the self through the space to the others. Cortex doi: 10.1016/j.cortex.2017.07.013 [Epub ahead of print].

Riva, G., and Gaudio, S. (2012). Allocentric lock in anorexia nervosa: new evidences from neuroimaging studies. Med. Hypotheses 79, 113-117. doi: 10.1016/j.mehy.2012.03.036

Riva, G., and Gaudio, S. (2017). Locked to a wrong body: eating disorders as the outcome of a primary disturbance in multisensory body integration. Conscious. Cogn. doi: 10.1016/j.concog.2017.08.006 [Epub ahead of print].

Riva, G., Gaudio, S., and Dakanalis, A. (2015). The neuropsychology of self objectification. Eur. Psychol. 20, 34-43. doi: 10.1027/1016-9040/a000190

Riva, G., Serino, S., Di Lernia, D., Pavone, E. F., and Dakanalis, A. (2017a). Embodied medicine: mens sana in corpore virtuale sano. Front. Hum. Neurosci. 11:120. doi: 10.3389/fnhum.2017.00120

Riva, G., Wiederhold, B. K., and Gaggioli, A. (2017b). A healthy mind in a healthy virtual body: the future of virtual health care, in Annu. Rev. Cybertherapy Telemed. 15, eds B. K., Wiederhold, G., Riva, C., Fullwood, A., Attrill-Smith, and G., Kirwan (San Diego, CA: Interactive Media Institute), 3-7. Available online at: http://www.arctt.info/volume-15-summer-2017

Runfola, C. D., Von Holle, A., Trace, S. E., Brownley, K. A., Hofmeier, S. M., Gagne, D. A., et al. (2013). Body dissatisfaction in women across the lifespan: results of the UNC-Self and gender and body image (GABI) studies. Eur. Eat. Disord. Rev. 21, 52-59. doi: 10.1002/erv.2201
Schmidt, U., and Treasure, J. (2006). Anorexia nervosa: valued and visible. A cognitive-interpersonal maintenance model and its implications for research and practice. Br. J. Clin. Psychol. 45, 343-366. doi: 10.1348/014466505x53902

Serino, S., and Dakanalis, A. (2017). Bodily illusions and weight-related disorders: clinical insights from experimental research. Ann. Phys. Rehabil. Med. 60, 217-219. doi: 10.1016/j.rehab.2016.10.002

Serino, S., Dakanalis, A., Gaudio, S., Carrà, G., Cipresso, P., Clerici, M., et al. (2015). Out of body, out of space: impaired reference frame processing in eating disorders. Psychiatry Res. 230, 732-734. doi: 10.1016/j.psychres.2015.10.025

Serino, S., Pedroli, E., Keizer, A., Triberti, S., Dakanalis, A., Pallavicini, F., et al. (2016a). Virtual reality body swapping: a tool for modifying the allocentric memory of the body. Cyberpsycholol. Behav. Soc. Netw. 19, 127-133. doi: 10.1089/cyber.2015.0229

Serino, S., Scarpina, F., Keizer, A., Pedroli, E., Dakanalis, A., Castelnuovo, G., et al. (2016b). A novel technique for improving bodily experience in a non-operable super-super obesity case. Front. Psychol. 7:837. doi: 10.3389/fpsyg.2016.00837

Seth, A. K., Suzuki, K., and Critchley, H. D. (2012). An interoceptive predictive coding model of conscious presence. Front. Psychol. 2:395. doi: 10.3389/fpsyg. 2011.00395

Sterling, P. (2012). Allostasis: a model of predictive regulation. Physiol. Behav. 106, 5-15. doi: 10.1016/j.physbeh.2011.06.004

Stice, E. (2016). Interactive and mediational etiologic models of eating disorder onset: evidence from prospective studies. Annu. Rev. Clin. Psychol. 12, 359-381. doi: 10.1146/annurev-clinpsy-021815-093317

Stice, E., Rohde, P., Shaw, H., and Gau, J. (2011). An effectiveness trial of a selected dissonance-based eating disorder prevention program for female high school students: long-term effects. J. Consult. Clin. Psychol. 79, 500-508. doi: $10.1037 / \mathrm{a} 0024351$

Tajadura-Jiménez, A., Banakou, D., Bianchi-Berthouze, N., and Slater, M. (2017). Embodiment in a child-like talking virtual body influences object size perception, self-identification, and subsequent real speaking. Sci. Rep. 7:9637. doi: 10.1038/s41598-017-09497-3

Tajadura-Jiménez, A., and Tsakiris, M. (2014). Balancing the "inner" and the "outer" self: interoceptive sensitivity modulates self-other boundaries. J. Exp. Psychol. Gen. 143, 736-744. doi: 10.1037/a0033171

Talsma, D. (2015). Predictive coding and multisensory integration: an attentional account of the multisensory mind. Front. Integr. Neurosci. 9:19. doi: $10.3389 /$ fnint.2015.00019

Treasure, J., and Schmidt, U. (2013). The cognitive-interpersonal maintenance model of anorexia nervosa revisited: a summary of the evidence for cognitive, socio-emotional and interpersonal predisposing and perpetuating factors. J. Eat. Disord. 1:13. doi: 10.1186/2050-2974-1-13

Tseng, H. H., Bossong, M. G., Modinos, G., Chen, K. M., McGuire, P., and Allen, P. (2015). A systematic review of multisensory cognitive-affective integration in schizophrenia. Neurosci. Biobehav. Rev. 55, 444-452. doi: 10.1016/j.neubiorev. 2015.04.019

Wang, J., Mathalon, D. H., Roach, B. J., Reilly, J., Keedy, S. K., Sweeney, J. A., et al. (2014). Action planning and predictive coding when speaking. Neuroimage 91, 91-98. doi: 10.1016/j.neuroimage.2014.01.003

Weser, V., Finotti, G., Costantini, M., and Proffitt, D. R. (2017). Multisensory integration induces body ownership of a handtool, but not any handtool. Conscious. Cogn. 56, 150-164. doi: 10.1016/j.concog.2017.07.002

Zopf, R., Contini, E., Fowler, C., Mondraty, N., and Williams, M. A. (2016). Body distortions in anorexia nervosa: evidence for changed processing of multisensory bodily signals. Psychiatry Res. 245, 473-481. doi: 10.1016/j. psychres.2016.09.003

Conflict of Interest Statement: The authors declare that the research was conducted in the absence of any commercial or financial relationships that could be construed as a potential conflict of interest.

Copyright $\odot 2018$ Riva and Dakanalis. This is an open-access article distributed under the terms of the Creative Commons Attribution License (CC BY). The use, distribution or reproduction in other forums is permitted, provided the original author(s) and the copyright owner are credited and that the original publication in this journal is cited, in accordance with accepted academic practice. No use, distribution or reproduction is permitted which does not comply with these terms. 